\title{
Pathway to Ascertain the Role of Pharmacogenomics in Healthcare Utilization Outcomes [Response to
} Letter]

\author{
Paul Y Takahashi' \\ Euijung Ryu ${ }^{2}$ \\ James R Cerhan $\mathbb{1 D}^{3}$ \\ Suzette J Bielinski (D) ${ }^{3}$ \\ Janet E Olson ${ }^{3}$ \\ 'Division of Community Internal \\ Medicine, Department of Internal \\ Medicine, Mayo Clinic, Rochester, MN, \\ USA; ${ }^{2}$ Division of Biomedical Statistics \\ and Informatics, Department of Health \\ Sciences Research, Mayo Clinic, \\ Rochester, MN, USA; ${ }^{3}$ Division of \\ Epidemiology, Department of Health \\ Sciences Research, Mayo Clinic, \\ Rochester, MN, USA
}

\section{Dear editor}

We appreciate the thoughts of Dr. Roman and his comments. We understand that the number of identified pharmacogenomic genes continues to increase with time, and the clinical utility also increases with time and expert opinion. We chose these selected pharmacogenes because of their strong clinical practice recommendations and the data available at the time of the gene selection. ${ }^{1}$ Due largely to the efforts associated with other initiatives within the RIGHT study, our clinical practice set up specific electronic medical record best practice alerts for these pharmacogenes, and it was believed that there was the potential for change in clinical care for patients with extreme phenotypes. ${ }^{2}$ We did not design the study to specifically look at all pharmacogenomic genes.

We agree that the ideal goal would be to study specific drug/gene pairs. In our limitation section, we described the problems of not including specific drug/gene pairs and specific causes of hospitalizations or ED visits. ${ }^{3}$ In this real-world pharmacogenomic implementation study, we did not have a sufficient number of patients with the specific drug exposures, the high-risk genotypes, and clearly recorded electronic record documentation of side effects and lack of effectiveness. We also had to rely upon medication prescriptions rather than medications dispensed. Therefore, our alternate goal was to determine if PGx genes could be used as potential biomarkers for adverse health outcomes. In our previous pilot study, we found that patients with ultrarapid metabolizer of CYP 2D6 had higher risk of hospital utilization. ${ }^{4}$ Thus, we had hope that potentially expanding the number of pharmacogenomic genes would continue to show an effect. We agree and hope that as pharmacogenomics becomes more widespread, the ability to look at specific drug/gene pairing will be more feasible.

Lastly, we agree that there are practical limitations to the use of observational cohort studies to study pharmacogenomics. As described above, this includes the need for a very large sample size to compensate for the low likelihood of medication usage among those carrying the extreme phenotypes (those most likely to demonstrate a clinical effect), as well as inconsistent documentation of lack of efficacy and side effects. There is also the potential for bias and confounding in any observational design. However, there are also high costs involved with conducting clinical trials of pharmacogenomics which also limit the utility of this design for
Correspondence: Paul Y Takahashi Division of Community Internal Medicine Department of Internal Medicine, Mayo Clinic, 200 First Street SW, Rochester, MN, 55905, USA

Tel + I-507-284-25II

Fax + I-507-266-2297

Email Takahashi.paul@mayo.edu 
addressing many important questions. We look forward to seeing data from larger observational cohorts that may address some of the limitations inherent to our study.

\section{Disclosure}

We have nothing to disclose.

\section{References}

1. Bielinski SJ, St Sauver JL, Olson JE, et al. Cohort profile: the right drug, right dose, right time: using genomic data to individualize treatment protocol (RIGHT Protocol). Int J Epidemiol. 2020;49(1):23-24k. doi:10.1093/ije/dyz123
2. Caraballo PJ, Bielinski SJ, St Sauver JL, Weinshilboum RM. Electronic medical record-integrated pharmacogenomics and related clinical decision support concepts. Clin Pharmacol Ther. 2017;102 (2):254-264. doi:10.1002/cpt.707

3. Takahashi PY, Ryu E, Bielinski SJ, et al. No association between pharmacogenomics variants and hospital and emergency department utilization: a Mayo Clinic Biobank retrospective study. Pharmgenomics Pers Med. 2021;14:229-237. doi:10.2147/PGPM. S281645

4. Takahashi PY, Ryu E, Pathak J, et al. Increased risk of hospitalization for ultrarapid metabolizers of cytochrome P450 2D6. Pharmgenomics Pers Med. 2017;10:39-47. doi:10.2147/PGPM.S114211

Dove Medical Press encourages responsible, free and frank academic debate. The content of the Pharmacogenomics and Personalized Medicine 'letters to the editor' section does not necessarily represent the views of Dove Medical Press, its officers, agents, employees, related entities or the Pharmacogenomics and Personalized Medicine editors. While all reasonable steps have been taken to confirm the content of each letter, Dove Medical Press accepts no liability in respect of the content of any letter, nor is it responsible for the content and accuracy of any letter to the editor.

Pharmacogenomics and Personalized Medicine

\section{Publish your work in this journal}

Pharmacogenomics and Personalized Medicine is an international, peer-reviewed, open access journal characterizing the influence of genotype on pharmacology leading to the development of personalized treatment programs and individualized drug selection for improved safety, efficacy and sustainability. This journal is indexed on the American Chemical Society's Chemical Abstracts Service (CAS). The manuscript management system is completely online and includes a very quick and fair peer-review system, which is all easy to use. Visit http://www.dovepress.com/testimonials.php to read real quotes from published authors. 